\title{
Autorregeneração de fissuras em concreto a partir de uma cultura de bactérias
}

\author{
Self-regeneration of cracks in concrete from a bacteria culture \\ Autorregeneración de grietas en hormigón de una cultura de bacterias
}

Recebido: 04/05/2021 | Revisado: 09/05/2021 | Aceito: 15/05/2021 | Publicado: 30/05/2021

\author{
Marilú Carvalho da Silva Gato \\ ORCID: https://orcid.org/0000-0003-0471-7810 \\ Universidade da Amazônia, Brasil \\ E-mail: carvalhomarilu137@gmail.com \\ Wellington Muniz \\ ORCID: https://orcid.org/0000-0003-1891-6378 \\ Universidade da Amazônia, Brasil \\ E-mail: wellyngtonmuniz.37@gmail.com \\ Karina Barbosa da Silva \\ ORCID: https://orcid.org/0000-0002-6700-1804 \\ Universidade da Amazônia, Brasil \\ E-mail: karinasilvastm@hotmail.com \\ Márlison Santos de Sá \\ ORCID: https://orcid.org/0000-0001-7470-2636 \\ Universidade da Amazônia, Brasil \\ E-mail: 270102987@prof.unama.br
}

\begin{abstract}
Resumo
O concreto apresenta vantagens como a economia, maleabilidade, durabilidade, resistência, podendo apresentar baixa permeabilidade e custo de manutenção. No entanto, não é incomum, a ocorrência de fissuras, que podem ocorrer por causa de variações higrotérmicas, higroscópicas e outras. Tais fissuras são agravadas pela ação dos agentes de intemperismo. Neste sentido, o presente trabalho buscou verificar se o uso de bactérias ureolíticas, do tipo Bacillus subitilis, poderia corrigir as fissuras por meio do processo de biomineralização e pela conversão de nutrientes como lactato de cálcio em calcário por meio da precipitação do carbonato de cálcio. A amostra de Bacillus subitilis foi descoberta em chorume em um aterro sanitário, localizado na comunidade de Perema, município de Santarém-Pará, Brasil. Após a caracterização da amostra, teste de resistência a temperatura e preparação da solução bacteriológica, o conteúdo foi aplicado em fissuras de três corpos de prova com fissuras de $0,1 \mathrm{~mm}, 1 \mathrm{~mm}$ e $2 \mathrm{~mm}$. Após um período de seis dias as fissuras nos três CPs foram completamente regeneradas, mostrando a alta capacidade da Bacillus subitilis na calcificação das fissuras. Os resultados, portanto, mostraram-se promissores, direcionando o desenvolvimento de novas tecnologias neste campo, bem como despertando um outro olhar para a questão ambiental atrelada ao chorume.

Palavras-chave: Fissuras em concreto; Autorregeneração; Bactéria Bacillus subitilis.
\end{abstract}

\begin{abstract}
Concrete has advantages such as economy, malleability, durability, resistance, and may have low permeability and maintenance cost. However, the occurrence of cracks is not uncommon, which can occur due to hygrothermal, hygroscopic and other variations. Such cracks are aggravated by the action of weathering agents. In this sense, the present work sought to verify whether the use of ureolytic bacteria, of the type Bacillus subitilis, could correct the cracks through the process of biomineralization and by converting nutrients such as calcium lactate into limestone through the precipitation of calcium carbonate. The sample of Bacillus subitilis was discovered in leachate in a landfill, located in the community of Perema, municipality of Santarém-Pará, Brazil. After the characterization of the sample, temperature resistance test and preparation of the bacteriological solution, the content was applied to fissures of three specimens with fissures of $0.1 \mathrm{~mm}, 1 \mathrm{~mm}$ and $2 \mathrm{~mm}$. After a period of six days, the cracks in the three PCs were completely regenerated, showing the high capacity of Bacillus subitilis in the calcification of the cracks. The results, therefore, proved to be promising, directing the development of new technologies in this field, as well as awakening another look at the environmental issue linked to leachate.
\end{abstract}

Keywords: Concrete cracks; Self-regeneration; Bacillus subitilis bacteria.

\section{Resumen}

El concreto tiene ventajas tales como economía, maleabilidad, durabilidad, resistencia y puede tener una baja permeabilidad y costo de mantenimiento. Sin embargo, no es infrecuente la aparición de grietas, que pueden ocurrir debido a variaciones higrotérmicas, higroscópicas y de otro tipo. Estas grietas se ven agravadas por la acción de agentes meteorológicos. En este sentido, el presente trabajo buscó verificar si el uso de bacterias ureolíticas, del tipo Bacillus subitilis, podría corregir las grietas mediante el proceso de biomineralización y mediante la conversión de 
nutrientes como el lactato cálcico en caliza mediante la precipitación de carbonato cálcico. La muestra de Bacillus subitilis fue descubierta en lixiviados en un relleno sanitario, ubicado en la comunidad de Perema, municipio de Santarém-Pará, Brasil. Tras la caracterización de la muestra, ensayo de resistencia a la temperatura y preparación de la solución bacteriológica, se aplicó el contenido a fisuras de tres probetas con fisuras de $0,1 \mathrm{~mm}, 1 \mathrm{~mm}$ y $2 \mathrm{~mm}$. Después de un período de seis días, las grietas en los tres PC se regeneraron por completo, mostrando la alta capacidad del Bacillus subitilis en la calcificación de las grietas. Los resultados, por tanto, demostraron ser prometedores, orientando el desarrollo de nuevas tecnologías en este campo, además de despertar una nueva mirada a la problemática medioambiental ligada a los lixiviados.

Palabras clave: Grietas de hormigón; Autorregeneración; Bacterias Bacillus subitilis.

\section{Introdução}

No mercado, existem diversos tipos de concreto como o concreto simples, armado, protendido, usinado e outros. Dentre estes, o concreto armado se destaca pela sua grande aplicabilidade, sendo o mais utilizado em todo o mundo, atualmente.

O concreto apresenta vantagens como a economia, maleabilidade, durabilidade, resistência, podendo apresentar baixa permeabilidade e custo de manutenção. Entretanto, não é incomum, a ocorrência de fissuras, que podem ocorrer por causa de variações higrotérmicas, higroscópicas e outras. Sendo o processo de degradação acelerado pela ação dos agentes de intemperismo.

\subsection{Concreto armado}

Historicamente, o concreto armado perpassa pela grande descoberta do cimento Portland, ocorrida no ano de 1824, pelo inglês Joseph Aspdin. Por outro lado, em 1899, François Hennebique desenvolveu um processo construtivo inédito, que denominou de "béton armé", cujo termo em português é "concreto armado" ou "concreto reforçado". Este tipo de concreto é aplicado em todo o mundo atualmente. A inovação do processo construtivo de François solucionou problemas de ligação e engastamento relacionados aos elementos estruturais como viga, pilar e laje. Mais tarde, François aplicou pela primeira vez essa tecnologia, projetando e construindo o primeiro edifício e a primeira ponte, ambos feitos em concreto armado e estão situados na França (Helene et al., 2010).

Para Helene et al. (2010), o concreto é constituído por quatro materiais: cimento Portland, água, agregado graúdo e agregado miúdo. Misturando esses 4 elementos, eles darão origem ao material sólido. Após a mistura e solidificação, o resultado é um concreto com potencial para ter alta durabilidade, alta resistência mecânica e alta impermeabilidade (Wilbert $e t$ al., 2017).

Ainda nos dias atuais, o concreto armado é o material estrutural de construção civil mais usado no mundo. Isso se deve principalmente à sua alta confiabilidade. No entanto, assim como as rochas, ele também é vulnerável aos agentes físicos, químicos e biológicos de intempere (Castanier et al., 1999). Por consequência, é uma tendência que o concreto sendo mal dimensionado, quando exposto às condições ambientes, apresente uma diminuição das suas propriedades mecânicas (Góis, 2016).

\subsection{Fissuras no concreto armado}

As fissuras surgem em função das tensões de tração nas estruturas de concreto. São consideradas manifestações patológicas. Destaca-se que essas manifestações podem surgir logo após a concretagem, como também ao longo do seu processo de ganho de resistência. No entanto, existem muitas outras variáveis para essas manifestações (Bertolini, 2010).

De acordo com Mukherjee et al. (2015) o surgimento de fissuras, pode ser oriundo tanto das atividades humanas, fenômenos naturais ou até pelo envelhecimento das construções. Esses fatores consequentemente podem possibilitar a entrada de agentes agressivos, causando assim, oxidação no aço e também influenciam diretamente na vida útil da edificação. 
As manifestações patológicas podem aparecer em qualquer elemento estrutural, seja nos pilares, vigas ou lajes. Essas anomalias na maior parte acontecem em função da solicitação de esforço ultrapassar a resistência dos elementos.

Os rompimentos classificam-se como: fissura, trinca, rachadura, fenda e brecha (Figueiredo, 1989). Essas anomalias foram classificadas por Zazarini (2016), levando-se em consideração a espessura da abertura, conforme mostra o Quadro 1.

Quadro 1 - Classificação dos rompimentos em função da espessura de abertura

\begin{tabular}{|c|c|}
\hline CLASSIFICAÇÃo & $\begin{array}{c}\text { Espessura da abertura } \\
\text { (milímetros) }\end{array}$ \\
\hline Fissura & Até 0,5 \\
\hline Trinca & Maior que 0,5 até 1,5 \\
\hline Rachadura & Maior que 1,5 até 5,0 \\
\hline Fenda & Maior que 5,0 até 10 \\
\hline Brecha & Maior que 10 \\
\hline
\end{tabular}

Fonte: Adaptado de Zazarini (2016).

Ao longo do presente trabalho, utiliza-se a expressão fissura para qualquer abertura, para efeito de simplificação. Segundo Oliveira (2012), as fissuras têm duas classificações em relação a variação nas dimensões da abertura, são elas: as dinâmicas - são aquelas que visivelmente estão aumentando de abertura e comprimento; e a inativa - cujas dimensões da abertura não evoluem. As fissuras passivas, na prática, são causadas por: assentamento plástico, dessecação superficial, retração química ou intrínseca, movimentação das formas, variação térmica e sobrecargas. As fissuras ativas são decorrentes de: variações térmicas, retrações por secagem ou hidráulicas, cargas dinâmicas, corrosão da armadura, reações expansivas com sulfatos, e reação álcali-silicatos (Figueiredo, 1989).

\subsection{Bioprecipitação de cabonato de cálcio por bactérias ureolíticas}

A uréase é uma enzima que provém da sintetização de minerais. Esse processo também é denominado de bioprecipitação - precipitação de carbonato de cálcio pela ação de microrganismos. Dentre esses microrganismos destacam-se as bactérias (Hamdan et al., 2017).

Neste sentido, algumas espécies de bactérias são capazes de precipitar, em quantidades muito significativas, diversos tipos de cristais de carbonato de cálcio, tal como: a calcita, aragonita, vaterita e a dolomita, a partir do mesmo meio de cultura (Hammes et al. 2003). A atividade da uréase e do teor de carbonato de cálcio (CaCO3) precipitado dependem de fatores como: espécie e quantidade de bactérias, pH, temperatura e concentração de ureia e cálcio (Jiang et al. 2017).

$\mathrm{Na}$ natureza, existe uma diversidade considerável de espécies de bactérias. No que tange a precipitação do carbonato de cálcio, as bactérias Bacillus são muito utilizadas na biomineralização, pois possuem um metabolismo que consiste na uréase - uma enzima que modifica a ureia em gás carbônico e amônia (Torgal et al.,2013). As subespécies mais utlizadas para fins experimentais são: Bacillus subtilis, Bacillus pasteurii, Bacillus cohnii, Bacillus sphaericus (Anbu et al., 2016).

Muitos pesquisadores têm optado por essas bactérias também pelo fato de ocorrerem abundantemente em diversos ambientes (Achal et al., 2013). Portanto, um dos fatores mais importantes, a serem considerados em trabalhos sobre bioprecipitação, é a viabilidade econômica e instrumental para o isolamento das bactérias, já que algumas delas são encontradas em ambientes hostis como por exemplo, nos vulcões ativos. 


\subsection{Autorregeneração do concreto}

Pesquisas sobre autorregeneração do concreto são desenvolvidas desde 1970. A princípio, uma das principais pesquisas voltou-se para a cura autógena, isto é, quando o concreto auto regenera-se por meio do processo natural de hidratação tardia e carbonatação (Silva, 2007). Entretanto, logo identificou-se que essa reação química era muito demorada e limitada, pois a autorregeneração eficaz apenas ocorria em fissuras com aberturas $\leq 50 \mu \mathrm{m}$ (Schlangen et al., 2006). Tal processo se mostrou inviável, quando comparado aos materiais de correção de fissuras, tais como o epóxi e aditivo expansivo (Oliveira et al., 2015).

Entretanto, os reparos nas edificações a partir dos materiais de correção acarretam custos exacerbados. Nesse contexto, pesquisadores em diversos países buscaram na bioprecipitação uma alternativa para sanar o problema, como por exemplo, pela biodeposição (Dick et al., 2006). A biodeposição consiste no uso de microrganismos, que possuem a capacidade de precipitar carbonato de cálcio, o qual calcifica a região onde estes microrganismos são depositados, criando uma superfície protetora.

O bioconcreto ganhou mais relevância a partir da descoberta da bactéria Bacillus Pseudofirmus para esta aplicação. Tal descoberta, foi resultado da pesquisa do professor e microbiologista Henk Jonkers e o engenheiro Erik Schlangen. A pesquisa iniciou-se em 2006 com o propósito de diminuir os custos na reparação de fissuras nas estruturas de concreto (Jonkers et al. 2010). Henk Jonkers coletou a bactéria Bacillus pseudofirmus em um vulcão ativo, isto é, em ambiente altamente hostil e de $\mathrm{pH}$ acima de 10. O método utilizado no trabalho de Jonkers e equipe consistia em encapsular os esporos bacterianos em pastilhas de argila, juntamente com o lactato de cálcio, ademais, misturá-las ao concreto, onde ficavam adormecidas por um longo tempo, podendo durar até 200 anos, consequentemente, prolongando a vida útil do concreto. Quando ocorria a fissuração, as bactérias ficavam expostas ao ar ou água, e a partir desse momento elas ficavam ativas e alimentavam-se do lactato de cálcio, o qual consequentemente era convertido em calcário insolúvel, e este era depositado nas paredes da fissura, até que ocorresse o preenchimento total. Como consequência do trabalho de Jonkers, desenvolveu-se uma solução em spray, que pode ser aplicado diretamente na manifestação patológica.

Figura 1. Autorregeneração do concreto.

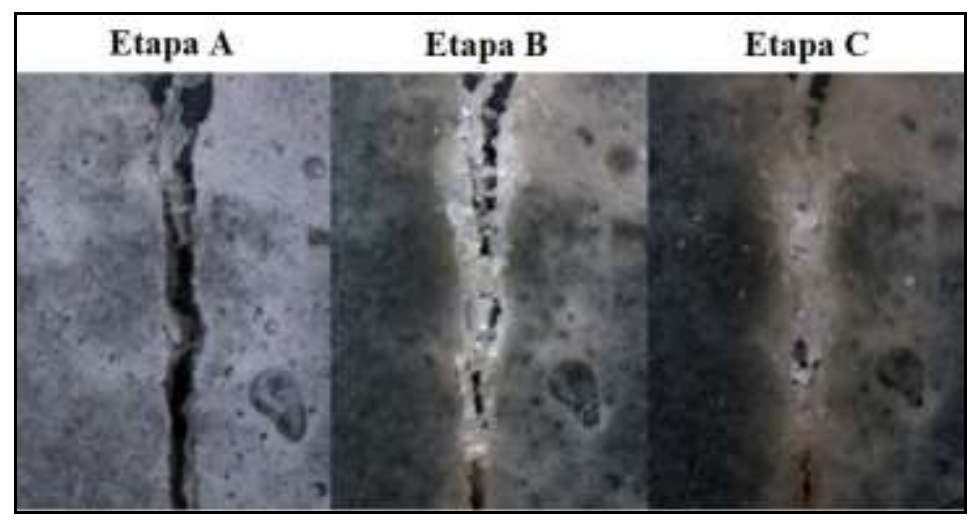

Fonte: Adaptado de Stewart (2015).

A Figura 1 retrata três etapas da regeneração do concreto. Na etapa (A) a ocorrência da fissura, na etapa (B) início da regeneração e na etapa (C) observa-se a completa auto cura do concreto.

É importante ressaltar que essa autorregeneração só era eficaz para fissuras de até $8 \mathrm{~mm}$ (Jonkers, 2011). A figura 1 mostra o processo de autorregeneração da fissura no concreto no trabalho de Jonkers.

Neste sentido, o presente trabalho buscou verificar se o uso de bactérias ureolíticas, do tipo Bacillus subitilis, 
encontradas em chorume em um aterro sanitário em Santarém-PA, Brasil, poderiam corrigir as fissuras por meio do processo de biomineralização e pela conversão de nutrientes como lactato de cálcio em calcário, por meio da precipitação do carbonato de cálcio. Tal abordagem é de grande relevância no que se refere a inovação em tecnologia de concreto.

Além disso, o uso do chorume para implementação da solução regenerativa traz implicações ambientais importantes, levando-se em consideração o fato de que a indústria da construção civil é uma das que mais poluem na atualidade e o chorume pode poluir mananciais e aquíferos subterrâneos. Portanto, o presente trabalho apresenta-se relevante também do ponto de vista ambiental.

\section{Metodologia}

A descrição metodológica do presente trabalho encontra-se descrita em cinco etapas: Etapa 1 - Seleção do método de preparação do bioconcreto, Etapa 2 - Coleta da bactéria Bacillus subitillis no chorume, Etapa 3 - Análise das colônias, Etapa 4 - Teste de temperatura e Etapa 5 - Aplicação da solução bacteriológica no concreto.

\section{Etapa 1 - Seleção do método de preparação do bioconcreto}

Existem dois métodos utilizados para desenvolvimento do bioconcreto. No primeiro, aplica-se a solução bacteriológica e o lactato de cálcio diretamente no concreto. Assim que ocorre a fissura, as bactérias se ativarão, alimentandose do lactato de cálcio, culminando na calcificação.

O segundo método consiste no uso de grânulos de argila com bactérias encapsuladas juntamente com o lactato de cálcio. Em seguida os grânulos são misturados as matrizes cimentícias. Quando ocorre a fissura as pastilhas de argilas se rompem, desencadeando o processo de calcificação (Silva et al., 2018).

Dessa maneira para o presente trabalho optou-se por definir a bactéria Bacillus subitillis como agente da biomineralização - por conta da hipótese de que pudesse ser encontrada em aterros sanitários onde ocorre lixiviação de calcário. Como também utilizar o método de aplicação direta na fissura, sem encapsulamento para diminuir custos.

\section{Etapa 2 - Coleta da bactéria Bacillus subitillis no chorume}

As amostras de chorume foram coletadas no dia 12 de março de 2021, no aterro da Comunidade de Perema, no município de Santarém-PA, Brasil. Para tal, foram utilizados três coletores, uma caixa térmica, duas seringas e fitas de medição de pH.

As medidas de $\mathrm{pH}$ apontaram que o chorume recebera material lixiviado de calcário por conta do período chuvoso, onde constatou-se que o líquido era alcalino. Foram retiradas 3 amostras no tanque de chorume, na parte superficial, a 1,5 m da borda. A coleta das amostras é apresentada na Figura 2. 
Figura 2. Autorregeneração do concreto.

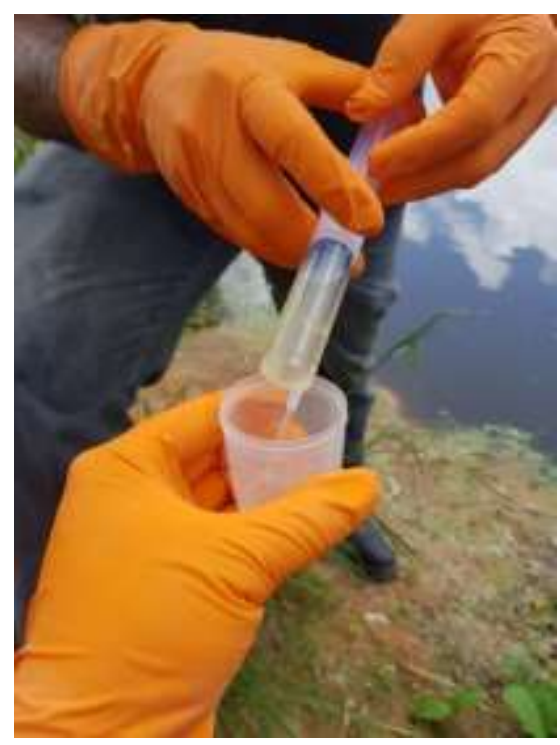

Fonte: Autores (2021).

Em seguida, as amostras foram levadas para o laboratório de microbiologia de um centro universitário local com a finalidade de semeá-las juntamente com lactato de cálcio nas placas de Petri contendo o meio de Agar Mueller Hinton, pois ele apresenta condições ideais para o crescimento de culturas de bactérias. Destaca-se que, ainda neste momento, a existência da bactéria Bacillus subitillis era uma hipótese. Para que a presença fosse confirmada ou não, era necessário promover o crescimento das colônias, para análise posterior. Para tal, as placas de Petri foram armazenadas em estufa calibrada na temperatura de $37^{\circ} \mathrm{C}$, onde permaneceram por 48 horas.

\section{Etapa 3 - Análise das colônias}

Após 48 horas na estufa, observou-se, que haviam muitas colônias na placa de Petri. Em seguida depositou-se parte do material em uma lâmina e realizou-se o teste de coloração de GRAM. Na figura 3 é possível observar a coloração azul violeta característico dos Bacillus gram positivos.

Figura 3. Análise microscópica da amostra do chorume.

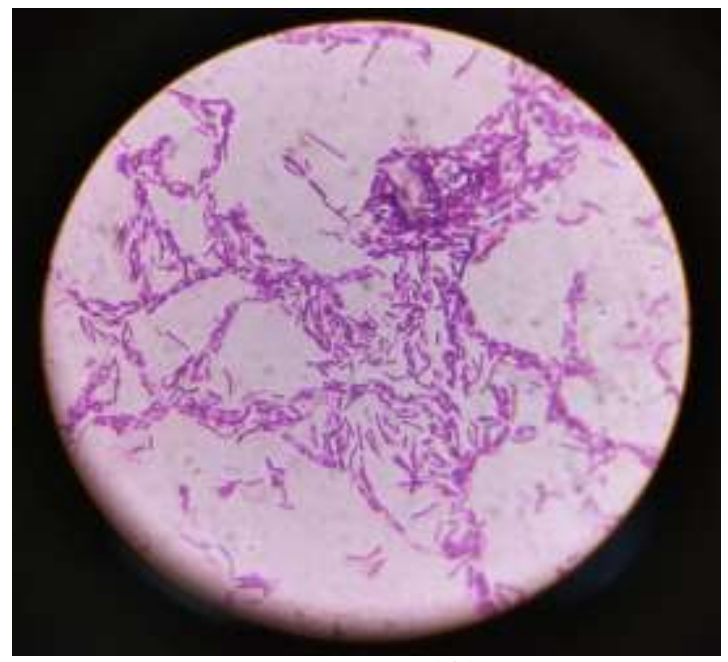

Fonte: Autores (2021). 


\section{Etapa 4 - Teste de temperatura}

Primeiramente realizou-se o cálculo da contagem dos microrganismos pela UFC (Unidade Formadoras de Colônia) para se quantificar o número de bactérias presente na solução antes e depois do teste de temperatura. Em seguida, as bactérias foram armazenadas em uma estufa e submetidas às temperaturas de $40^{\circ} \mathrm{C}, 50^{\circ} \mathrm{C}$ e $60^{\circ} \mathrm{C}$ durante 1 hora, respectivamente.

Após essa etapa, observou-se que as colônias de bactérias Bacillus subitilis são resistentes a elevadas temperaturas, pois não houve queda na quantidade de colônias, já indicando que se as mesmas fossem capazes de realizar a calcificação, poderiam facilmente ser aplicadas em concretos submetidos a condições equatoriais de temperatura.

Paralelamente, as colônias de bactérias no chorume que haviam ficado na estufa a $37{ }^{\circ} \mathrm{C}$ mostraram um acentuado crescimento, como mostra a Figura 4.

Figura 4. Placas de Petri com as colônias da Bacillus subitilis.

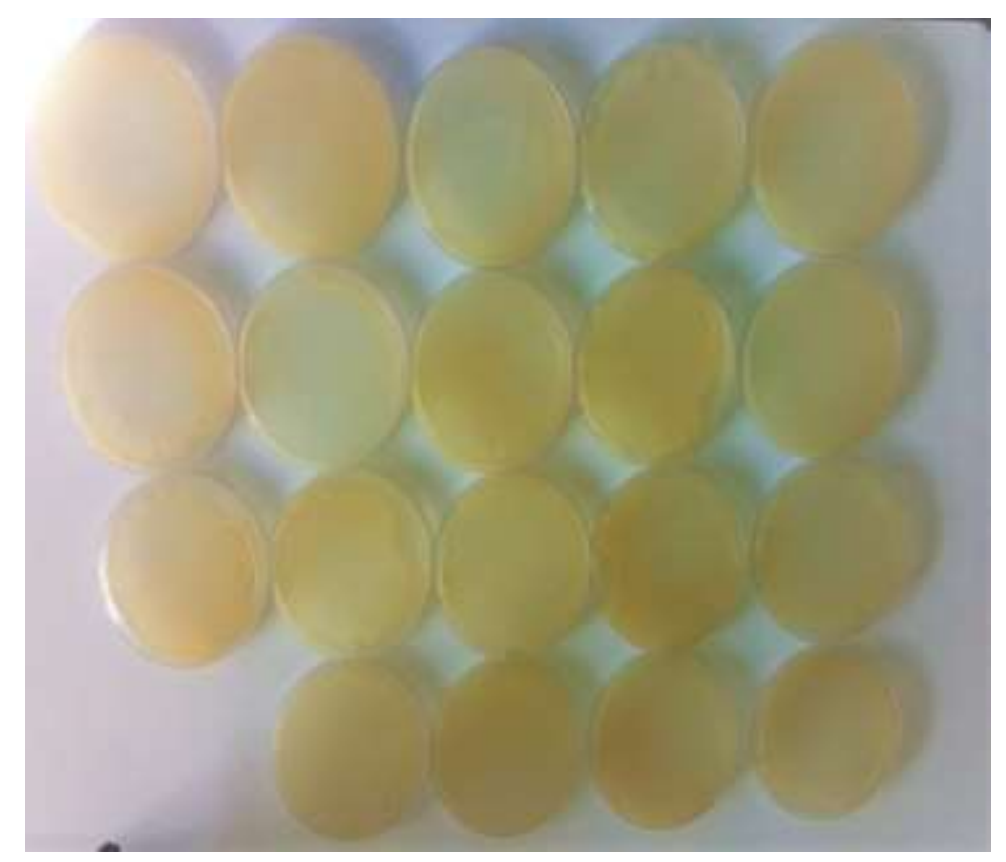

Fonte: Autores (2021).

Alguns trabalhos anteriores, como Jonkers (2011) apontavam a importância de investigação se o uso de matéria orgânica para sustento e aumento da colônia de bactérias. Em algumas, placas de Petri, à parte, foram semeadas colônias de bactérias onde acrescentou-se massa de coco de pupunha e açaí, frutas típicas da região norte, riquíssimas em nutrientes.

\section{Etapa 5 - Aplicação da solução bacteriológica no concreto}

Após 72 horas na estufa, as amostras de chorume foram retiradas e coletadas as colônias. Posteriormente, misturou-se $5 \mathrm{ml}$ de água estéreo, a solução bacteriológica estava elaborada.

Um mês antes destes procedimentos de laboratório, foram produzidos 7 CPs (Corpos de Prova) de acordo com a norma NBR 5738 (ABNT, 2015), conforme mostra a Figura 5. Destes, foram utilizados apenas 3, pelo fato do escopo do trabalho ter apenas a intensão de verificar se ocorreria a calcificação. Foram produzidos inicialmente $7 \mathrm{CPs}$, prevendo qualquer falha no processo de fissuramento.

As proporções para produção dos CPs foram: $5 \mathrm{~kg}$ de cimento, $8,5 \mathrm{~kg}$ de areia, 12,85 de brita tipo-1 e 2,4 litros de água. Pontua-se que a dosagem embasou-se no método ABCP, que se fundamenta na norma ACI 211.1-81 (Revised 85) - 
Standard Practice for Selecting Proportions for Normal, Heavyweight, and Mass Concrete, e que se assemelha a norma NBR 7211 (ABNT, 2005) - Agregados para concreto (Boggio, 2000).

Figura 5. Corpos de Prova.

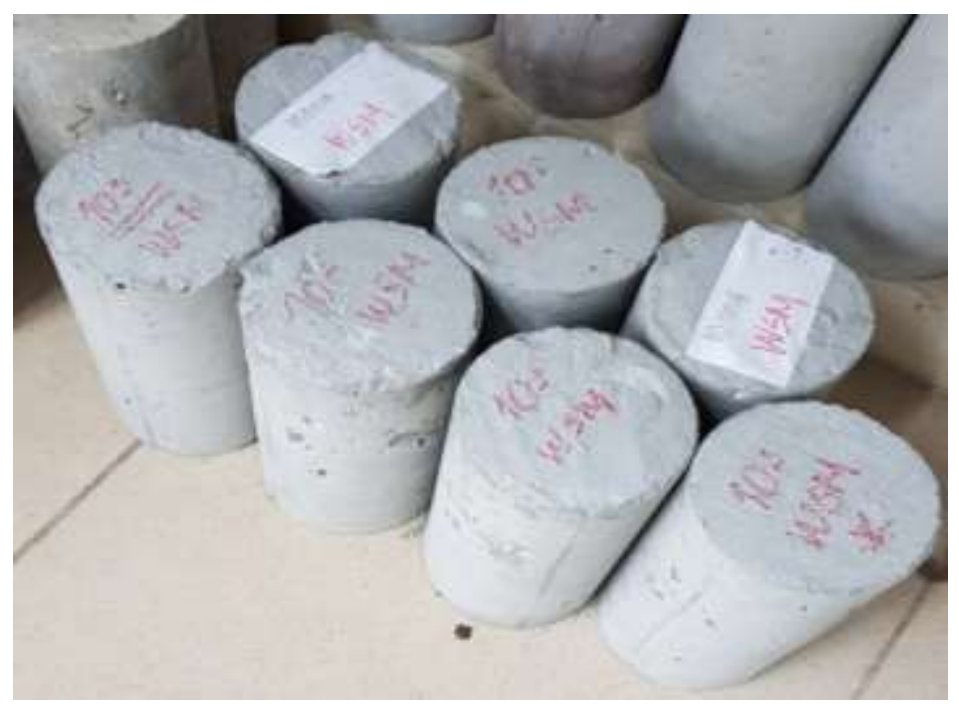

Fonte: Autores (2021).

O tipo de cimento utilizado foi o Portand II E-32, cujas características físico-químicas são apresentadas nas Tabelas 1 e 2 .

Tabela 1. Proporção em massa para composição do CP II-E-32 segundo a NBR 11578

\begin{tabular}{|c|c|c|c|}
\hline TIPO dE CIMENTO & CLÍNQUER E GESSO & $\begin{array}{c}\text { ESCÓRIA } \\
\text { GRANULAdA DE } \\
\text { ALTO-FORNO }\end{array}$ & $\begin{array}{c}\text { MATERIAL } \\
\text { CARBONÁtICO }\end{array}$ \\
\hline CP II-E-32 & $56-94 \%$ & $6-34 \%$ & $0-10 \%$ \\
\hline
\end{tabular}

Fonte: CSN (2020).

Tabela 2. Principais características físicas do cimento CP II-E-32.

\begin{tabular}{|c|c|c|c|c|c|c|c|c|c|c|}
\hline \multirow[b]{2}{*}{$\begin{array}{l}\text { TIPO DE } \\
\text { CIMENTO }\end{array}$} & \multirow[b]{2}{*}{ Classe } & \multicolumn{4}{|c|}{$\begin{array}{c}\text { RESISTÊNCIA À } \\
\text { COMPRESSÃO }\end{array}$} & \multirow{2}{*}{$\begin{array}{c}\text { FINURA } \\
\text { Residuo } \\
\text { na } \\
\text { Peneira } \\
75 \text { pm }\end{array}$} & \multicolumn{2}{|c|}{$\begin{array}{c}\text { TEMPO DE } \\
\text { PEGA }\end{array}$} & \multicolumn{2}{|c|}{ EXPANSIBILIDADE } \\
\hline & & $\begin{array}{c}\text { MPa } \\
3 \\
\text { dias }\end{array}$ & $\begin{array}{c}\text { MPa } \\
7 \\
\text { dias }\end{array}$ & $\begin{array}{c}\text { MPa } \\
28 \\
\text { dias }\end{array}$ & $\begin{array}{c}\text { MPa } \\
91 \\
\text { dias }\end{array}$ & & $\begin{array}{l}\text { Inicio } \\
\text { (horas) }\end{array}$ & $\begin{array}{c}\text { Fim } \\
\text { (horas) }\end{array}$ & $\begin{array}{l}\text { À frio } \\
(\mathrm{mm})\end{array}$ & $\begin{array}{c}\text { A quente } \\
\text { (mm) }\end{array}$ \\
\hline CP II & 32 & $\geq 10$ & $\geq 20$ & $\geq 32$ & - & $\leq 12,0$ & $\geq 1$ & $\leq 10$ & $\leq 5$ & $\leq 5$ \\
\hline
\end{tabular}

Fonte: CSN (2020).

A caracterização da dosagem de concreto dos CPs pode ser observado no Quadro 2. 
Quadro 2. Caracterização da dosagem de concreto.

\begin{tabular}{|c|l|}
\hline Cimento & $\begin{array}{l}\text { CP II - E-32 } \\
\gamma=3100 \mathrm{~kg} / \mathrm{m}^{3}\end{array}$ \\
\hline Areia & $\begin{array}{l}\mathrm{MF}=2,60 \text { Inch. } 30 \% \text { com } 6 \% \text { de umidade } \\
\gamma=2650 \mathrm{~kg} / \mathrm{m}^{3} \\
\delta=1470 \mathrm{~kg} / \mathrm{m}^{3} \text { (solta) }\end{array}$ \\
\hline Brita & $\begin{array}{l}\gamma=2700 \mathrm{~kg} / \mathrm{m}^{3} \\
\delta=1500 \mathrm{~kg} / \mathrm{m}^{3} \text { (compactada) } \\
\delta=1430 \mathrm{~kg} / \mathrm{m}^{3} \text { (solta) } \\
\delta=1400 \mathrm{~kg} / \mathrm{m}^{3} \text { (solta) } \\
\mathrm{D}_{\text {máx }}=25 \mathrm{~mm}\end{array}$ \\
\hline Concreto & $\begin{array}{l}\mathrm{F}_{\mathrm{ck}}=25 \mathrm{Mpa} \\
\mathrm{Abatimento}=90 \pm 10 \mathrm{~mm} \\
\mathrm{Sd}=5,5 \mathrm{mPa}\end{array}$ \\
\hline
\end{tabular}

Fonte: Autores (2021).

Os três CPs foram fissurados transversalmente, a partir de uma compressão perpendicular ao eixo longitudinal por uma prensa hidropneumática OP BR NR12 de uma empresa local. A compressão ocorreu de maneira gradativa até que ocorresse o rompimento. Com isto, cada $\mathrm{CP}$ foi separado em duas partes. Com o uso de um paquímetro de precisão da marca mitutoyo verificou-se que a abertura média dos CPs 1,2 e 3 eram, respectivamente $0,1 \mathrm{~mm}, 1 \mathrm{~mm}$ e $2 \mathrm{~mm}$. Cada CP possuía uma delimitação de $2 \mathrm{~cm}$ de perfil horizontal. A figura 6 retrata os CPs e as delimitações que foram feitas para a aplicação da solução bacteriana.

Figura 6. Corpos de prova, perfil horizontal e aberturas.

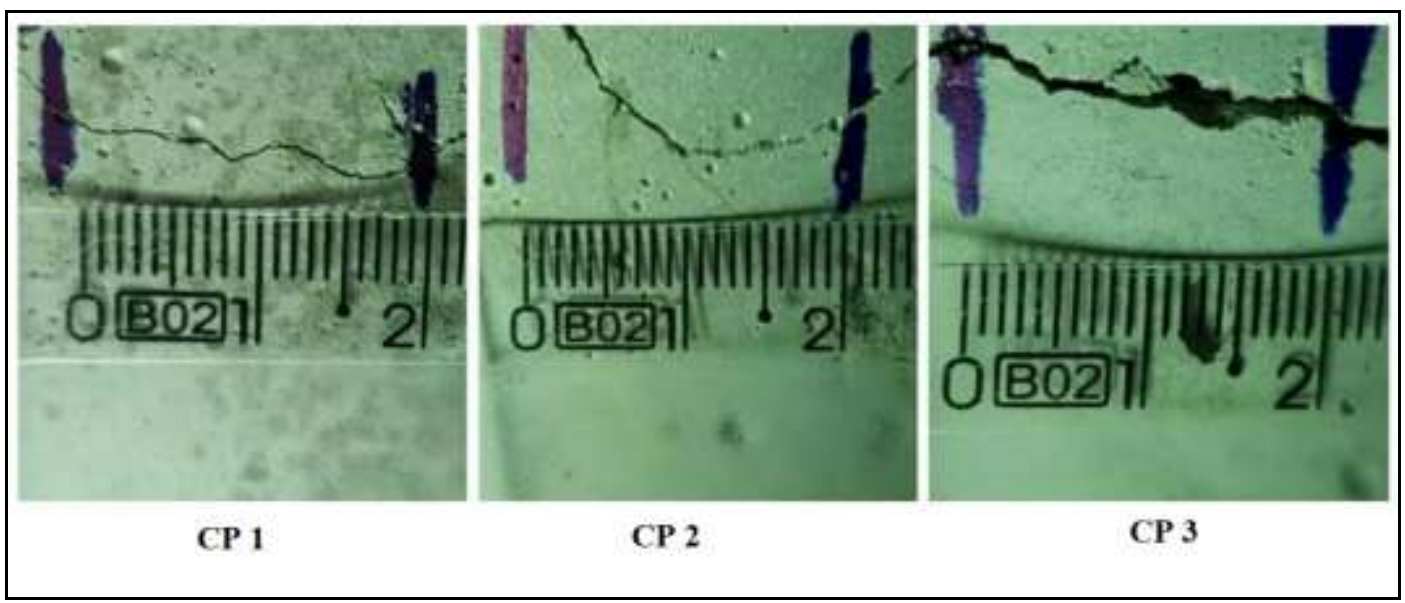

Fonte: Autores (2021).

Com a solução bacteriológica elaborada, forma líquida descrita na Figura 7, e os corpos de prova devidamente fissurados, realizou-se a aplicação da solução nas aberturas. Por se tratar de algo líquido, a aplicação apenas umedecia o local e depois de poucos minutos secava e tornava-se transparente. 
Figura 7. Aplicação da solução bacteriológica no concreto.

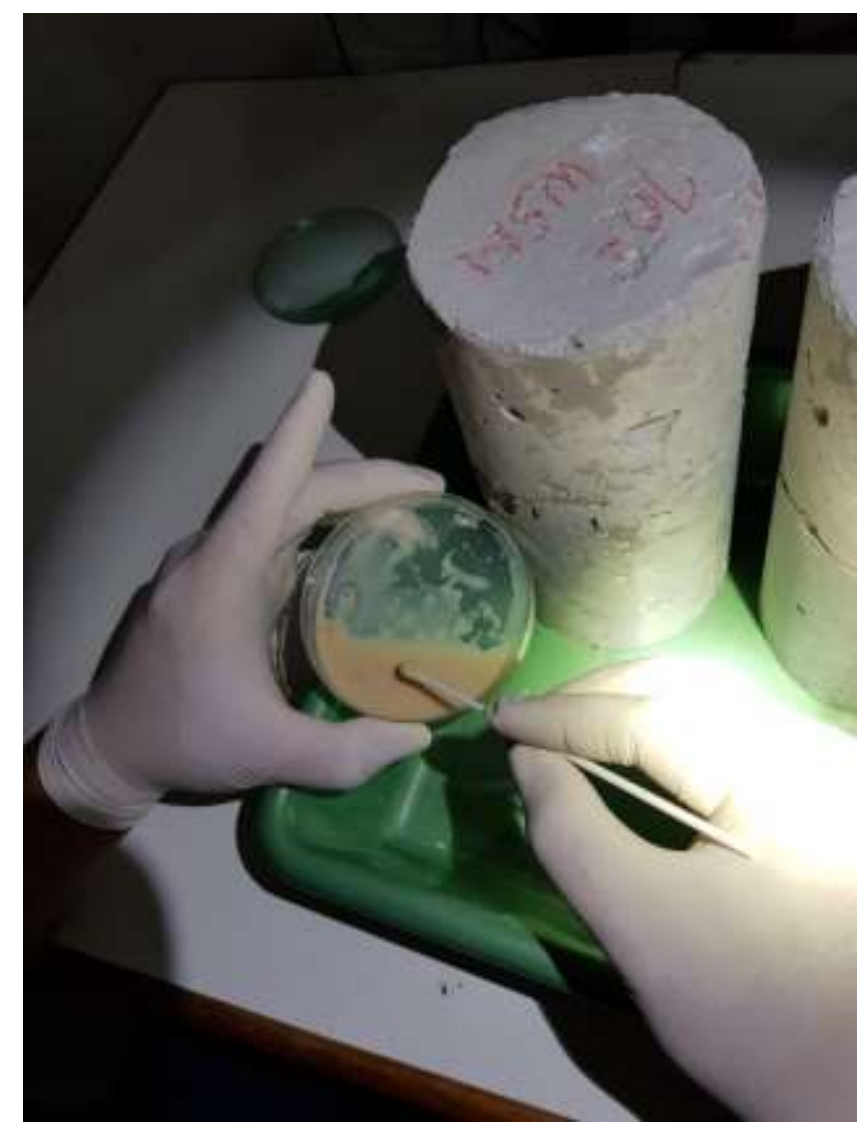

Fonte: Autores (2021).

Para a análise do processo de calcificação, além das observações diárias, foi realizada análise de espectroscopia de infravermelho (IR: Infrared). A espectroscopia na região do infravermelho é uma técnica de espectroscopia vibracional baseada em absorção molecular em que a energia, quando absorvida por uma determinada molécula, promove transições vibracionais e rotacionais (Silva, 2017). No presente trabalho, tal metodologia foi aplicada apenas com o intuito de verificar se caso houvesse a cristalização, se de fato tratava-se de calcificação. Para tal, os relatórios da análise de espectroscopia apontariam uma considerável concentração de cálcio nos cristais.

\section{Resultados e Discussão}

Após a aplicação da solução bacteriológica nas aberturas dos CPs, registrou-se o processo de autorregeneração ocorrido em um período de 6 dias (Figura 8). 
Figura 8. Processo de autorregeneração do concreto ao longo de 6 dias, após a aplicação da solução bacteriológica.

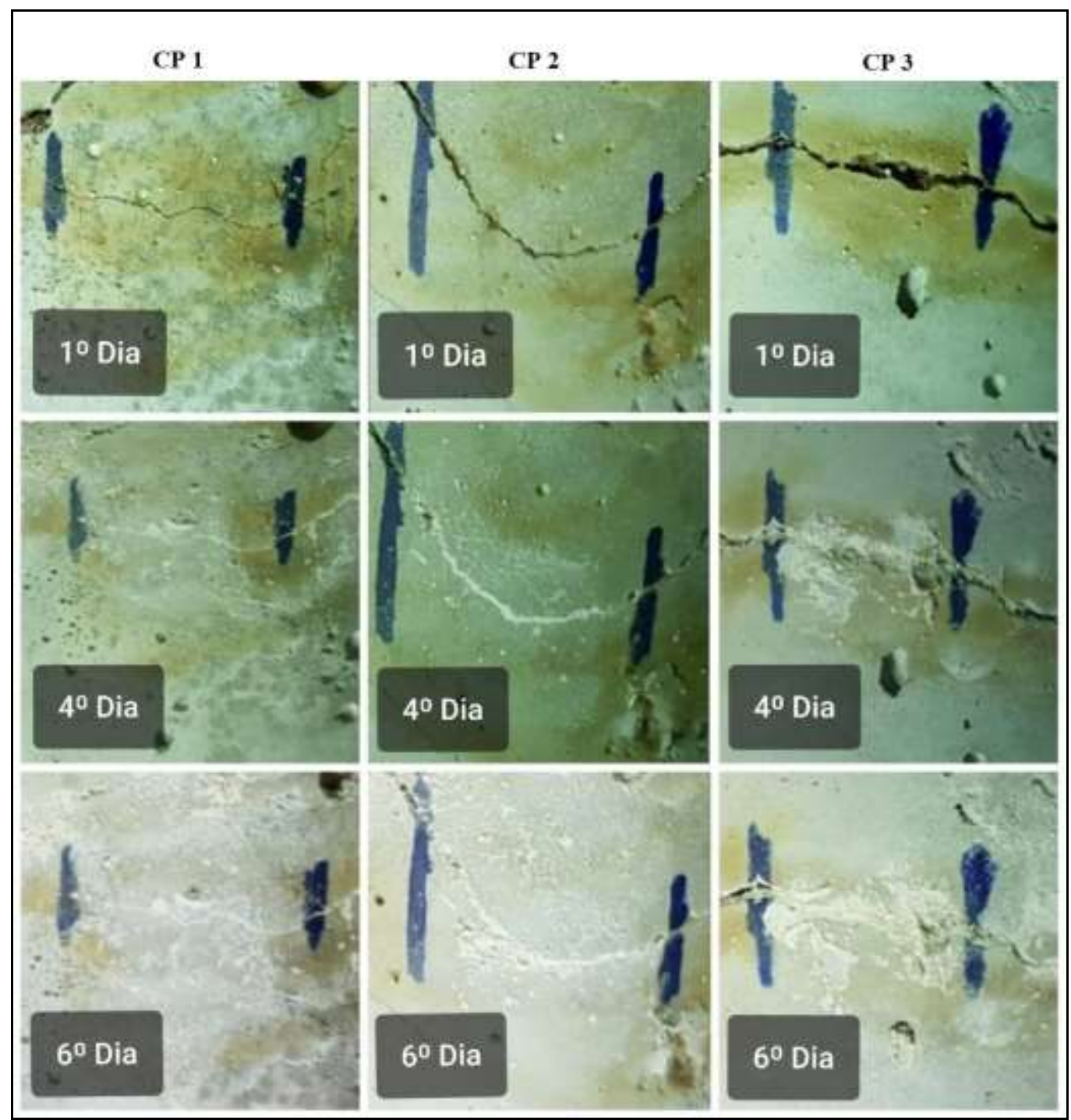

Fonte: Autores (2021).

A Figura 8 mostra a evolução temporal de autorregeneração ocorrida nos CPs 1, 2 e 3. A partir das primeiras $24 \mathrm{~h}$, já era possível observar a olho nu a formação de pequenos cristais brancos resultantes da ação das bactérias ureolíticas ao ficarem expostas ao oxigênio presente no ar.

Ainda nas primeiras 24h, houve a aderência das duas partes do CP 1, o que foi surpreendente. Nos dias posteriores, observou-se um aumento exponencial da cristalização, tanto nas aberturas como também nas faces dos CPs. Ao quarto dia, as aberturas já estavam completamente regeneradas. Ao sexto dia as culturas ainda causaram a cristalização em regiões além do perfil horizontal analisado, mostrando uma alta capacidade de expansão.

Estes resultados corroboram com os obtidos por Jonkers (2011), porém utilizando uma bactéria de mais fácil obtenção e sem os custos associados ao processo de encapsulamento.

Após o período de seis dias, parte do conteúdo resultante do processo de cristalização foi levado para análise em um laboratório de uma universidade local, onde foram realizados testes de espectroscopia afim de verificar qual a composição dos cristais. As análises apontaram para um material abundante em cálcio, com porcentagem de 97,5\% do teor total. Tal material possuía forte capacidade de aderência. 
A resistência a temperaturas elevadas típicas das regiões equatoriais, mostrou que o uso da bacillus subitilis é viável para aplicações onde o concreto ficará submetido a temperaturas mais elevadas. A observação da regeneração também, no que tange a variável temperatura, mostrou que essas colônias de bactérias apresentam maior taxa de calcificação quando sujeitas a temperaturas acima de $25^{\circ} \mathrm{C}$.

Pontua-se que, para transformar em produto de mercado a solução bacteriológica apresentada no presente trabalho, o grande desafio encontra-se em operacionalizar a coleta de chorume e o crescimento das colônias de bactérias.

As bactérias semeadas a parte, com a inserção de matéria orgânica, apresentou redução brusca da presença da bacillus subitilis. O processo de decomposição da matéria orgânica causou um aumento na acidez, diminuindo consideravelmente as colônias de bactérias bacillus subitilis, que são adaptadas às condições de pH elevado. Dessa forma, essas culturas se mostraram inviáveis para produção da solução bacteriológica. Entretanto ressalta-se que em estudos cujo o interesse sejam as bactérias gram positivas, que se adaptam a condições de maior acidez do meio, o uso de material orgânico rico em nutrientes pode se mostrar viável.

\section{Considerações Finais}

As manifestações patológicas em concreto são de grande interesse na Engenharia Civil, desde as causas, até as medidas de correção. O presente trabalho verificou que o uso de bactérias ureolíticas, do tipo bacillus subitilis, encontradas em chorume, podem corrigir as fissuras em concreto, por meio do processo de biomineralização e pela conversão de nutrientes como lactato de cálcio em calcário por meio da precipitação do carbonato de cálcio.

Para fissuras de $0,1 \mathrm{~mm}, 1 \mathrm{~mm}$ e $2 \mathrm{~mm}$, os resultados obtidos mostraram uma alta capacidade das bactérias na calcificação e correção em um período de quatro dias. Tais resultados corroboram com o desenvolvimento de inovações tecnológicas no campo da tecnologia de concreto, bem como desperta um outro olhar para a questão ambiental atrelada ao chorume.

Como sugestões para trabalhos posteriores, sugere-se o aprofundamento no desenvolvimento de novas tecnologias de encapsulamento de bactérias que aumentem a durabilidade da capacidade regenerativa do concreto, a partir de custos mais viáveis que os atuais. Outro estudo importante seria sobre as propriedades dos microcristais resultantes da calcificação, assim como sobre os efeitos deles nas propriedades mecânicas dos corpos de prova.

\section{Referências}

ABNT, Associação Brasileira de Normas Técnicas. (2005). NBR 7211: Agregados para concreto - Especificação.

ABNT, Associação Brasileira de Normas Técnicas. (2015). NBR 5738: Concreto - Procedimento para moldagem e cura de corpos-de-prova.

Achal, V., Mukerjee, A. \& Reddy, M. S. (2013, novembro). Biogenic treatment improves the durability and remediates the cracks of concrete structures. Construction and Building Materials. https://doi.org/10.1016/j.conbuildmat. 48, 1-5.

Anbu, P., Kang, C. H., Shin, Y. J., \& So, J. S. (2016, março). Formations of calcium carbonate minerals by bacteria and its multiple applications. SpringerPlus 5, 250. https://springerplus.springeropen.com/articles/10.1186/s40064-016-1869-2.

Bertolini, L. (2010, janeiro). Materiais de Construção: patologia, reabilitação, prevenção. Editora Oficina de textos.

Boggio, A. J. (2000). Estudo comparativo de métodos de dosagem de concretos de cimento Portland. http://hdl.handle.net/10183/12575. Programa de Pós Graduação de Engenharia Civil, Universidade Federal do Rio Grande do Sul, Brasil.

Castanier, S., Levrel, G. L. M., Orial, G. \& Perthuisot, J. P. (1999, julho). Ca-carbonates precipitation and limestone genesis - the microbiogeologist point of view. 126(1-4), 9-23. https://doi.org/10.1016/S0037-0738(99)00028-7. Editora Elsevier.

CSN. (2020). Eu entendo de cimento. Apostila treinamento. Companhia Siderúrgica Nacional. P. $13 . \quad$ https://www.csn.com.br/wpcontent/uploads/sites/452/2020/11/Apostila-Cimentos-1.pdf.

Dick, J., Windt, W. D., Graef, B. D., Saveyn, H., Meeren, P. V. D., Belie, N. D., Verstraete, W. (2006, agosto). Bio-deposition of a calcium carbonate layer on degraded limestone by Bacillus species. https://pubmed.ncbi.nlm.nih.gov/16491305/. 
Figueiredo, E. J. P. (1989, março). Terapia das construções de concreto: metodologia de avaliação de sistemas epóxi destinadas a injeção de fissuras passivas das estruturas de concreto. https://lume.ufrgs.br/handle/10183/1335. Dissertação de Mestrado, Universidade Federal do Rio Grande do Sul, Porto Alegre, RS, Brasil.

Góis, T. S. (2016). Estudo da corrosão do concreto microbiologicamente induzida (CCMI) em estruturas de saneamento. https://lemac.ufes.br/sites/lemac.ufes.br/files/field/anexo/Thais\%20Gois.pdf. Dissertação de Mestrado, Universidade Federal do Espírito Santo, ES, Brasil.

Hamdan, N., Kavazanjian, E., Rittmann, B. E., \& Ismail Karata, I. (2017). Carbonate Mineral Precipitation for Soil Improvement Through Microbial Denitrification. Geomicrobiology Journal, 34: 2, pp. 139-146. https://doi.org/10.1080/01490451.2016.1154117.

Hammes, F., Boon, N., Villiers, J., Verstraete, W., \& Siciliano, S.D. (2003, agosto). Strain-Specific Ureolytic Microbial Calcium Carbonate Precipitation. 4901-4909.VOL 69, Applied And Environmental Microbiology, pp. 4901-4909. https://www.ncbi.nlm.nih.gov/pmc/articles/PMC169139/.

Helene, P., \& Andrade, T. (2010). Concreto de cimento portland. https://www.phd.eng.br/wp-content/uploads/2014/07/lc48.pdf.

Jiang, N. \& Soga, K. (2017, janeiro). The applicability of microbially induced calcite precipitation (MICP) for internal erosin control in gravel-sand mixtures. https://tinyurl.com/4vvte6hx. Géotechnique, 67(1), 42-45.

Jonkers, H. Self-Healing Concrete. Revista Ingenia Magazine, UK, 46, 39-46, https://www.ingenia.org.uk/getattachment/Ingenia/Issue-46/SelfHealingConcrete/Arnold.pdf.

Jonkers, H. M., Thijssen, A., Muyzer, G., Copuroglu, O., \& Schlangen, E. (2010, fevereiro). Application of bacteria as self-healing agent for the development of sustainable concrete. Ecological Engineering, 36,. 230-235. https://doi.org/10.1016/j.ecoleng.2008.12.036.

Mukherjee, A., Varenyam, A. (2015, dezembro). A biological route for producing low energy binders. https://www.researchgate.net/publication/271079305_A_BIOLOGICAL_ROUTE_FOR_PRODUCING_LOW_ENERGY_BINDERS.

Oliveira, A., Becker, C. M. \& Amico, S. C. (2015). Avaliação das características da resina epóxi com diferentes aditivos desaerantes. Conferência: $23^{\mathrm{a}}$ Conferência Australasiana sobre Mecânica de Estruturas e Materiais, Em: Byron Bay, Austrália. 2. https://doi.org/10.1590/0104-1428.1661.

Oliveira, A. M. (2012, julho). Fissuras, trincas e rachaduras causadas por recalque diferencial de fundações. Trabalho de Conclusão de Curso. http://gdl.handle.net/1843/BUOS-9A3GCW. Universidade Federal de Minas Gerais. Belo Horizonte, MG, Brasil.

Schlangen, E., Heide, N., \& Breugel, K. V. (2006). Crack healing of early age cracks in concrete. https://link.springer.com/chapter/10.1007/978-1-4020-51043_32. In: KONSTA-GDOUTOS M.S. (eds) Measuring, Monitoring and Modeling Concrete Properties. Springer 273-284.

Silva, C. S. (2017). Espectroscopia no Infravermelho para Aplicações Forenses: documentoscopia e identificação de sêmen em tecidos. Tese de Doutorado. https://repositorio.ufpe.br/bitstream/123456789/29654/1/TESE\%20Carolina\%20Santos\%20Silva.pdf. Universidade Federal de Pernambuco, PE, Recife, Brasil.

Silva, D. G., Melo, L. A., (2018). Aplicação de bactérias biocimentantes no tratamento de patologias de revestimentos de argamassa. https://repositorio.ifg.edu.br/bitstream/prefix/208/1/tcc_Daniel\%20Silva_Lucas\%20Melo.pdf. Instituto Federal de Educação, Ciência e Tecnologia de Goiás, Aparecida de Goiânia, GO, Brasil.

Silva, E. F. (2007, dezembro). Variações dimensionais em concretos de alto desempenho contendo aditivo redutor de retração. Tese de Doutorado http://www.coc.ufrj.br/pt/component/docman/?task=doc_download\&gid=889\&Itemid=. Universidade do Rio de Janeiro.

Stewart, A. (2015, janeiro). The 'living concrete' that can heal itself. Delft University. http://edition.cnn.com/2015/05/14/tech/bioconcrete-delft-jonkers/.

Torgal F. P. \& Labrinchab, J.A. (2013, agosto). Biotechnologies and bioinspired materials for the construction industry: an overview. https://tinyurl.com/yz9ad264. International Journal of Sustainable Engineering, Editora Taylor \& Francis. Pp. 2-7.

Wilbert, D. G. B., Kazmierczak, C. S., \& Kulakowski, M. P. (2017). Análise da interface entre agregados reciclados de concreto e argamassas de concretos com cinza de casca de arroz e fíler basáltico por nanoindentação. https://doi.org/10.1590/s1678-86212017000200156. Revista Ambiente Construído - Revista On Line da Associação Nacional de Tecnologia do Ambiente Construído - ANTAC. 17.

Zanzarini, J. C. (2016). Análise das causas e recuperação de fissuras em edificação residencial em alvenaria estrutural - Estudo de caso. Trabalho de Conclusão de Curso. http://repositorio.roca.utfpr.edu.br/jspui/bitstream/1/6879/1/CM_COECI_2016_1_15.pdf. Universidade Federal do Paraná. 